\title{
Investigation of the Potential of Sedimentation in Geomorphologic Facies in Gonabad Township Using Wind Tunnel and IRIFR1 Model
}

\section{ART I C L E I N F O}

\section{Article Type}

Original Research

\section{Authors}

Mohammadnia M.*1 $M A$

Amirahmadi A. ${ }^{1} \mathrm{PhD}$,

Zanganeh Asadi MA. ${ }^{1} \mathrm{PhD}$
How to cite this article Mohammadnia M, Amirahmadi A, Zanganeh Asadi MA. Investigation of the Potential of Sedimentation in Geomorphologic Facies in Gonabad Township Using Wind Tunnel and IRIFR1 Model. Geographical Researches. 2019;34 (4):577-586.
${ }^{1}$ Department of Geomorphology, Geography Faculty, Hakim Sabzevari University, Sabzevar, Iran

\section{*Correspondence}

Address: Faculty of Geography and Environmental Sciences, Campus of Hakim Sabzevari University, Tohid Shahr, Sabzevar, Iran

Phone: +98 (51) 57251576

Fax: +98 (51) 57231474

malihe.mohamadnia@yahoo.com

\section{Article History}

Received: September 27, 2019

Accepted: December 1, 2019

ePublished: December 11, 2019

\section{A B S T R A C T}

Aims \& Backgrounds Considering the fact that a large part of our country is in arid and semi-arid regions and every year wind erosion and dust storms cause significant damages to the country's bioeconomic resources, it is necessary to study this phenomenon. This study investigated the erosion rate of geomorphological facies of Gonabad city in relation to wind erosion.

Methodology The wind erosion intensity was determined using wind tunnel and experimental model of IRIFR1. In the region, 17 facies were identified and mountainous and non-covered areas and areas that were not potentially dusty were excluded from the study. Sampling operations were performed on the remaining 14 facies. The samples were weighed and placed in a wind tunnel at $10 \mathrm{~m} / \mathrm{s}$ for 10 minutes and then weighed again. The weight difference indicates the amount of wind erosion from a given level. Also in the IRIFR1 model 14 facies were weighted according to expert opinion.

Findings According to the results of wind tunnel, wind erosion in the study area was highest in sand dune facies and in low and high plains and relatively high water erosion was lowest and according to IRIFR1 model in sand dunes was highest and in low and high plains and low water erosion and high pebbles were the least. Wind erosion sensitivity map was prepared in the study area and divided into five classes of rock mass and non-erosion, very low sensitivity, low, medium and high sensitivity. Conclusion Given that according to the analysis of samples in the wind tunnel, more than $28 \%$ of the area is in the medium to high sensitivity class, applying soil protection techniques against wind erosive power such as windbreakers, seeding and grazing reduction in these areas (especially the area Northwest) seems necessary.

Keywords Wind Erosion; Geomorphological Facies; Wind Tunnel; IRIFR1; Gonabad Township

\section{CIT A T I O N L INKS}

[Alipour, et al; 2014] Estimating wind erosion potential and sediment potential using the IRIFR method in Miandasht Esfarayen ...; [Alipour, et al; 2016] Estimation of wind erosion severity in Alaa Region of Semnan using IRIFR.E.A ...; [Amin \& Taqizadeh Mehrejerdi; 2016] Investigating soil erodibility in arid and hyper-arid regions of Iran case study: Yazd-Ardakan ...; [Azim Zade \& Ekhtesasi; 2004] Investigating the effect of physical and chemical properties of soil on the rate of wind erosion speed, case study: YazdArdakan ...; [Ayazi, et al; 2016] Investigating the possibility of sedimentation in geomorphological fancies using wind tunnel and IRIFREA, case study: Aran district of ...; [Ebrahimi Dorcheh, et al; 2010] Estimating wind erosion via ...; [Ekhtesasi \& Zare Chahouki; 2006] Wind erosion values of IRIFER model and comparison with wind erosion meter case study: Segzi plain in Esfahan ...; [Fister \& Ries; 2009] Wind erosion in the central ebro basin under changing land use ...; [Hangen;1976] A wind erotion predication system to meet user ...; [Hanifeh Pour \& Mashhadi; 2013] Survey of agricultural resistance to wind erosion in southeast ...; [Ildermi \& Moradi;2017] Estimating wind erosion intensity using the IRIF.E.A model case study: Ghahavand plain of ...; [Jafari Shalkuhi, et al; 2015] Evaluating effective factors on the stabilization of mineralized soils against wind to prevent the accumulation of ...; [Kochemi Sardo, et al; 2017] Evaluation of the IRIFR model for simulating soil loss in different facies of Wind Erosion Using Wind Erosion Measurement ...; [Kusumandari; 2014] Soil erodibility of several types of green open space areas in Yogyakarta city, ...; [Memarian Khalil Abad \& Safdari; 2008] Deposits of wind deposits in the fedsheh area of ...; [Mohammad Khan \& Kashfi; 2015] The directions of winding sand in Ardestan region by comparing morphometric time of sand dunes and wind ...; [Movahedan, et al; 2013] Laboratory study of the effect of polyvinyl acetate on the erosion of various soil soils against ...; [Saremi Naieni; 2016] Estimate the frequency of speed and the direction of the erosion of winds and produces dust storms and dust at the level of Yazd province using the windrose ...; [Sharratt, et al; 2007] Loss of soil and PM10 from agricultural fields associated with high winds on the Columbia ...; [Webb, et al; 2016] Threshold wind velocity dynamics as a driver of aeolian sediment mass ...; [Zobeck \& Van Pelt; 2006] Wind-induced dust generation and transport mechanics on a bare agricultural field; 
معلق، جهشى و خزشى انجام مىشود و سبب ايجاد خسارتهاى

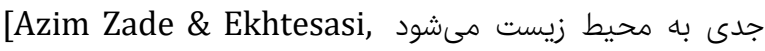
[2004. فرسايش بادى در مناطقى با بارندگى كمتر از 10 ميلى ميلى مترد

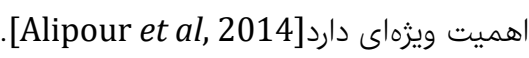

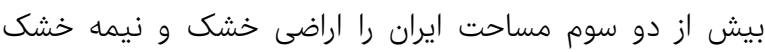

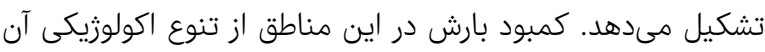
كاسته و يوشش گياهى با تراكم كم بر روى آن استقرار يافته است.

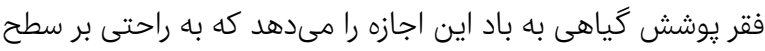

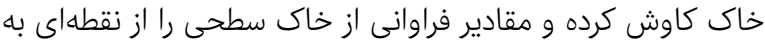
نقطه ديكر حمل كند [Memarian Khalil Abad et al, 2008] جابهجايى خاك و از بينرفتن آن در קنين مناطين

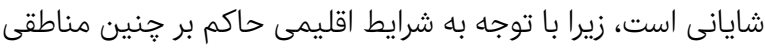
تشكيل خاك كند است [Ebrahimi Dorcheh et al, 2010].

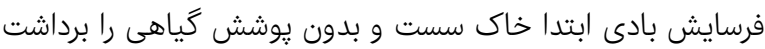

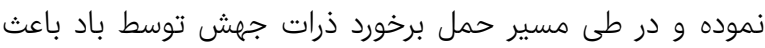

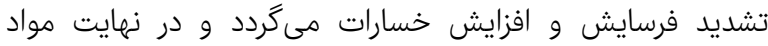

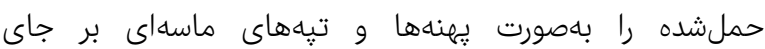
مى گذارد[Mohamad Khan \& Kashfi, 2015]. فرسايش بادى آل و معضلات مربوط به آن هر ساله خسارات سنكينى به بخشهاى

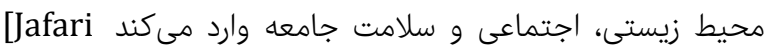

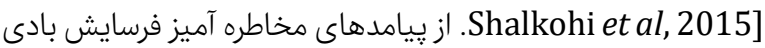

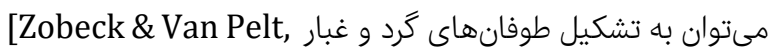

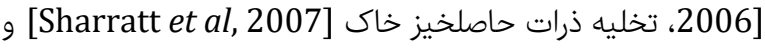
ايجاد يوششى مزاحم بر سطح اراضى زراعى و و غيرزراعى

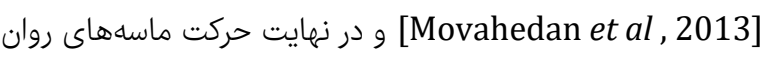
اشاره كرد. هنكامى كه سرعت باد از يك آستانه مشخص بيشتر شود

فعاليت تخريبى آن آغاز مىشود [Hangen, 1976]. كشور ايران بر روى كمربند جهانى بيابانزايى و فرسايش بادى إنى قرار

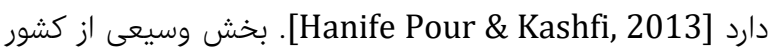
ايران را مناطق خشك و فرا خشك در بركرفته است، كه به دليل

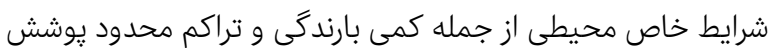

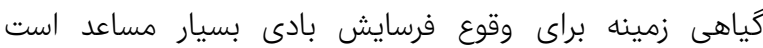

[Alipour et al, 2016]

فيستر و ريس [Fister \& Rise, 2009]، با استفاده از تونل قابل حمل ميزان فرسايش بادى را در حوضه Ebro برآورد نمودند. براى

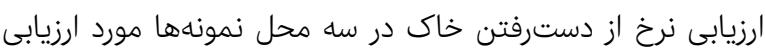

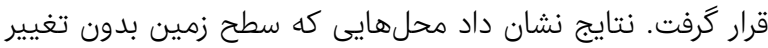
بوده كمترين ميزان فرسايش بادى را دار داشته است. كوسوماندارى

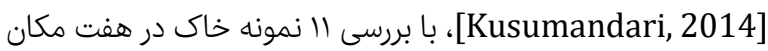

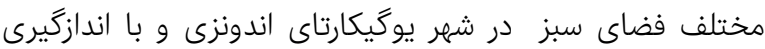

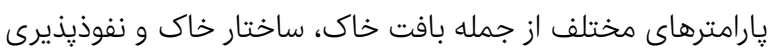

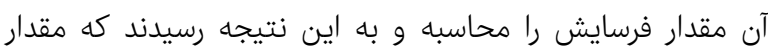

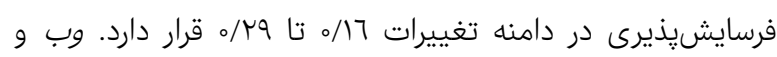
همكاران [Webb et al, 2016]، به برآورد آستانه فرسايش بادى داري
توان رسوبزايى در رخسارههاى زئومورفولوزى

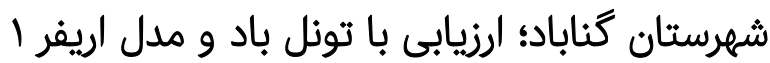

MA مليحه محمدنيا" كروه زئومورفولوزى، دانشكده جغرافيا، دانشكاه حكيم سبزوارى، سبزوار، ايران

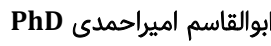
كروه زئومورفولوزى، دانشكده جغرافيا، دانشكاه حكيم سبزوارى، سبزوار، ايران محمدعلى زنكنه اسدى PhD كروه زئومورفولوزى، دانشكده جغرافي إنيا، دانشكاه حكيم سبزوارى، سبزوار، ايران

جكيده اهداف و زمينهها: با توجه به اينكه بخش وسيعى از ايران در مناطق خشك و ورائ

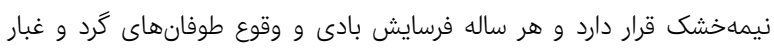

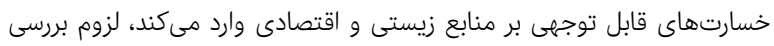

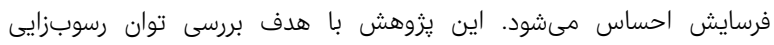

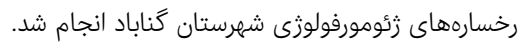

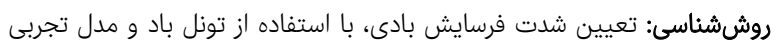

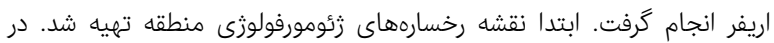

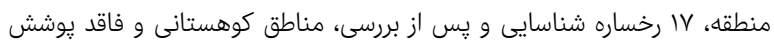

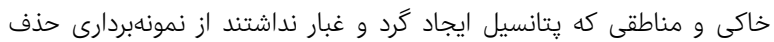

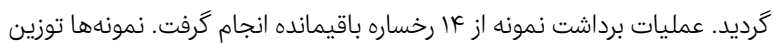

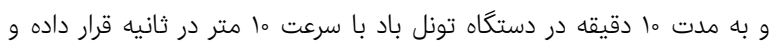

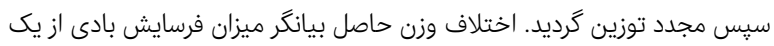

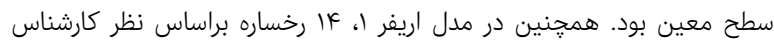

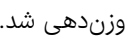
يافتهها: براساس نتايج تونل باد، ميزان فرسايش بادى در منطقه مورد مطالعه در

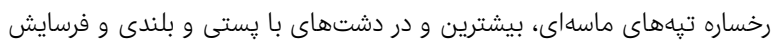

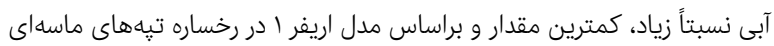

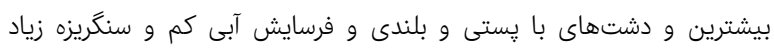

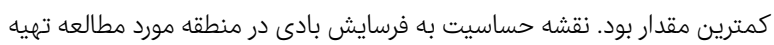

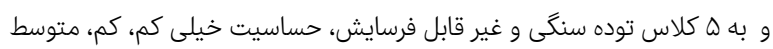
و زياد تقسيم شد.

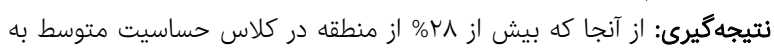

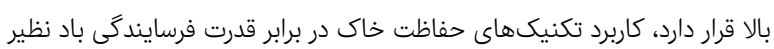

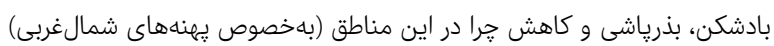

ضرورى است. كليدواثهها: فرسايش بادى، رخسارههاى زئومورفولوزى، تونل باد، IRIFR1، كناباد

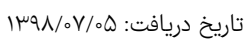

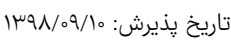

"نويسنده مسئول: malihe.mohamadnia@yahoo.com

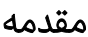

باد از جمله عوامل اصلى ايجاد فرسايش و تخريب در سطح زمين

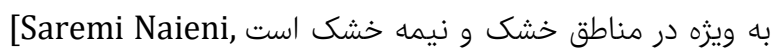

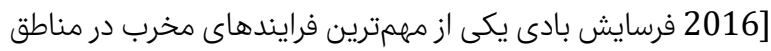

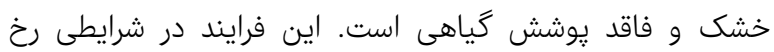

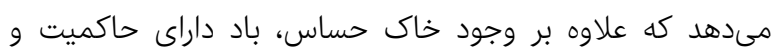
سرعت قابل توجه باشد. انتقال ذرات خاك به صورتهاى باد مختلف داري 


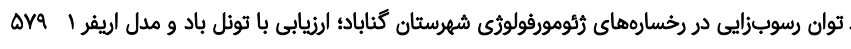

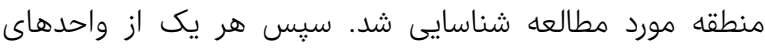
در پينج مكان در نيومكزيكو پرداختند. نتايج نشان داد در فصول و

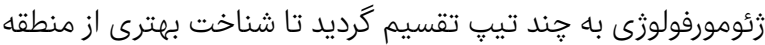

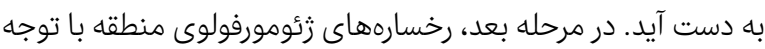

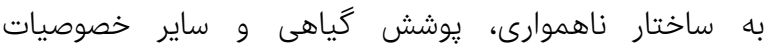

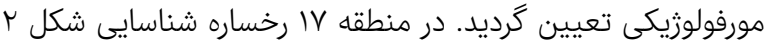

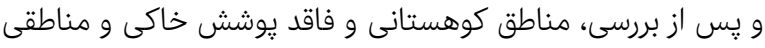

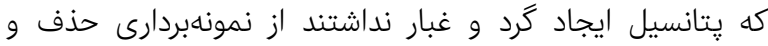

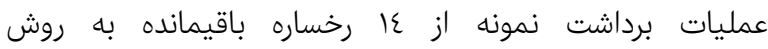

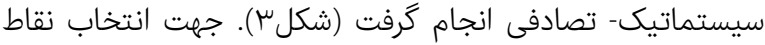

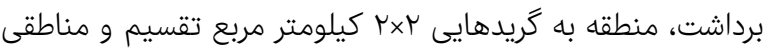

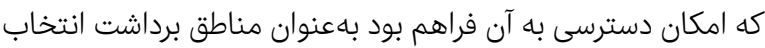

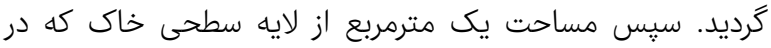
معرض فرسايش بادى قرار داشت بهعنوان نمونه، برداشت سيس مرديس

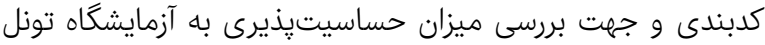

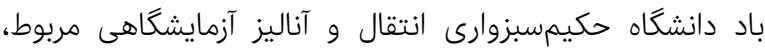
بهمنظور تعيين درجه حساسيت نمونه نسبت به فرسايش بادى

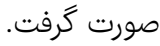

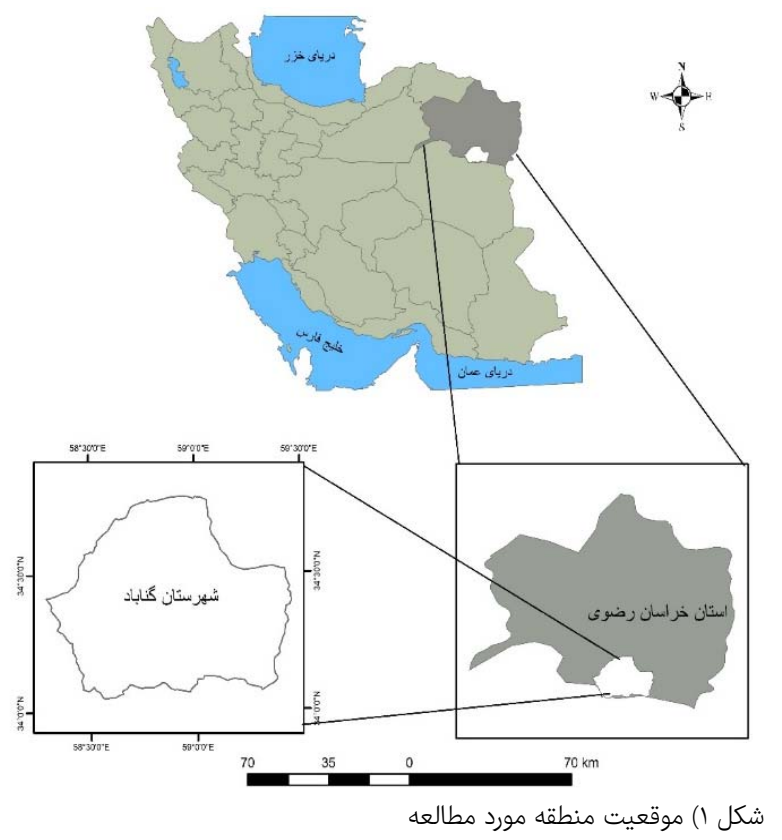

اندازگيرى مقدار رسوبدهى و فرسايش بادى به كمك دستگاه سنجش فرسايش بادى مدرى دستخاه سنجش فرسايش بادى، در واقع نوعى تونل باد آزمايشگاهى بادى

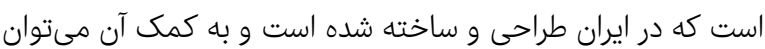
بسيارى از عوامل موثر در فرسايشيذيرى خاك از جمله سرانه

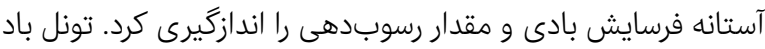

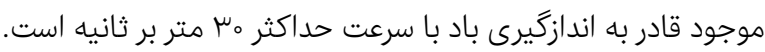
ابعاد محفظه آزمايش تونل هع×هـ سانتىمتر است (شكل ع). جهت برآورد ميزان حساسيتيذيرى هر رخساره، ابتدا رسوبات باتِ

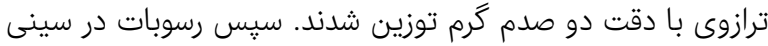




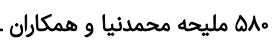

ناهموارى، سرعت و وضعيت باد، عامل خاك و يوشش غير زنده،

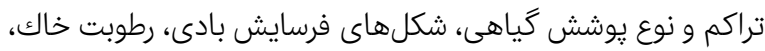

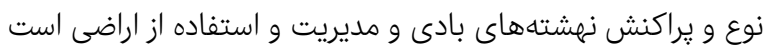
كه در هر يك از واحدهاى كارى امتيازدهى و براساس جمع امتيازات به دست آمده و با استفاده از رابطه ا توان رسوب دهاب دهى اراضى بـ برآورد

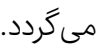
$\mathrm{Qs}=41[\operatorname{EXP}(0.05 \mathrm{R})]$

رابطه (1) كه در آن Qs: ميزان رسوبدهى سالانه بر حسب تن در كيلومتر

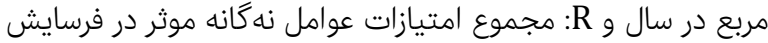

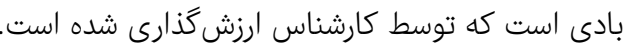

كه بدين منظور طراحى گرديده بود قرار گرفته و به مدات ده ده دقيقه

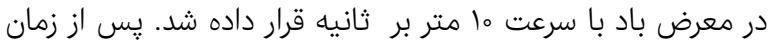
مذكور مجدد رسوبات وزن شده و اختلاف وزن حاصله بيانكر ميزان

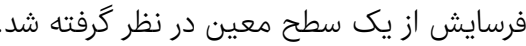
برآورد شدت فرسايش بادى و ميزان رسوبدهى به كمك مدل IRIFR1 مدل تجربى IRIFR1 از جمله مدلهاى شاخصى است كه براساس

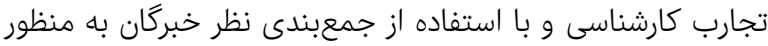

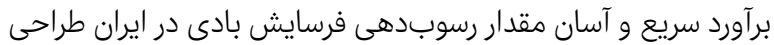
و ارايه شده است [Ekhtesasi, 2006]. شاخص سورس مورد استفاده و

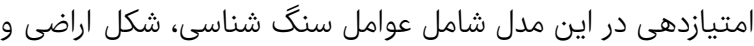

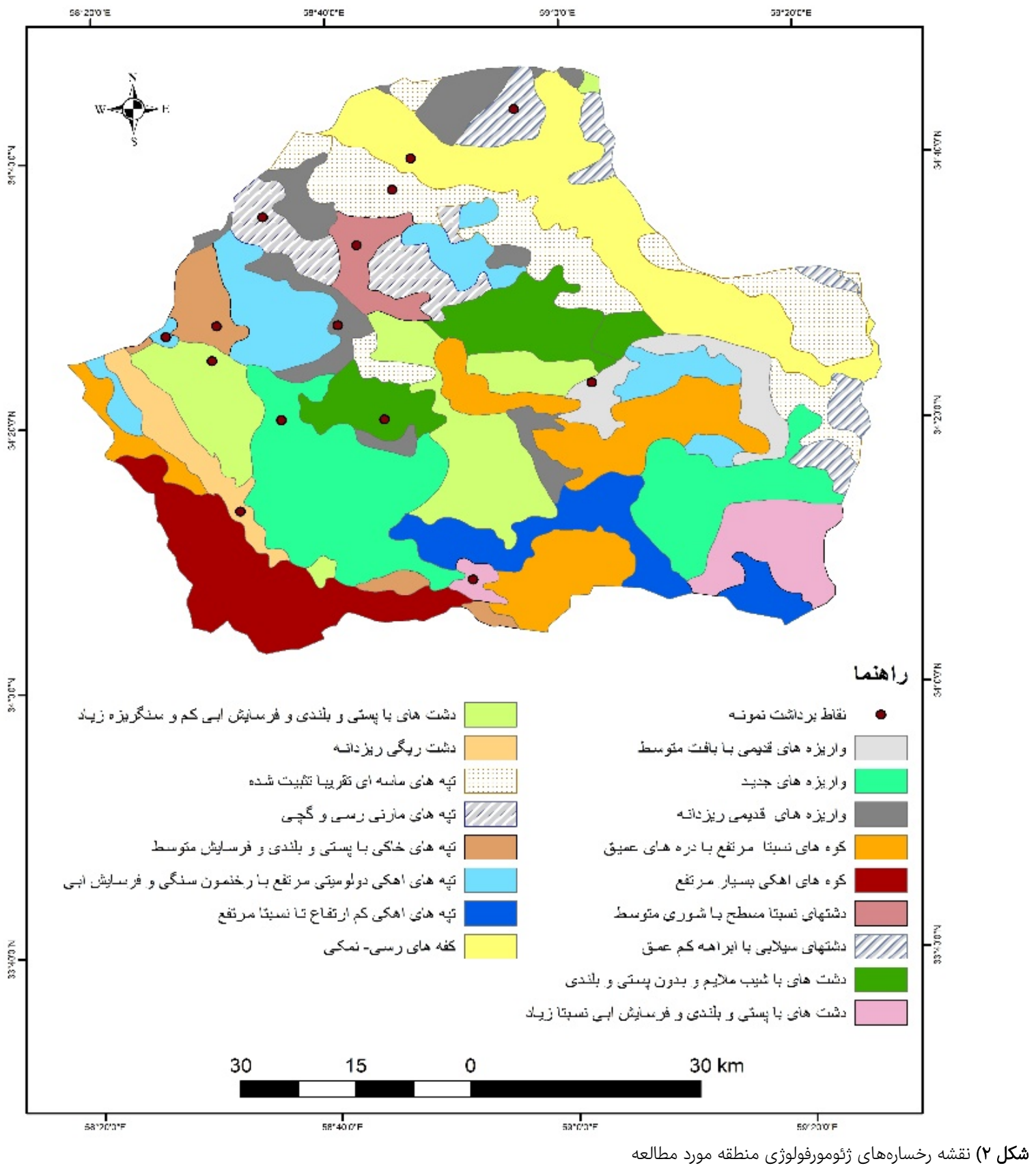



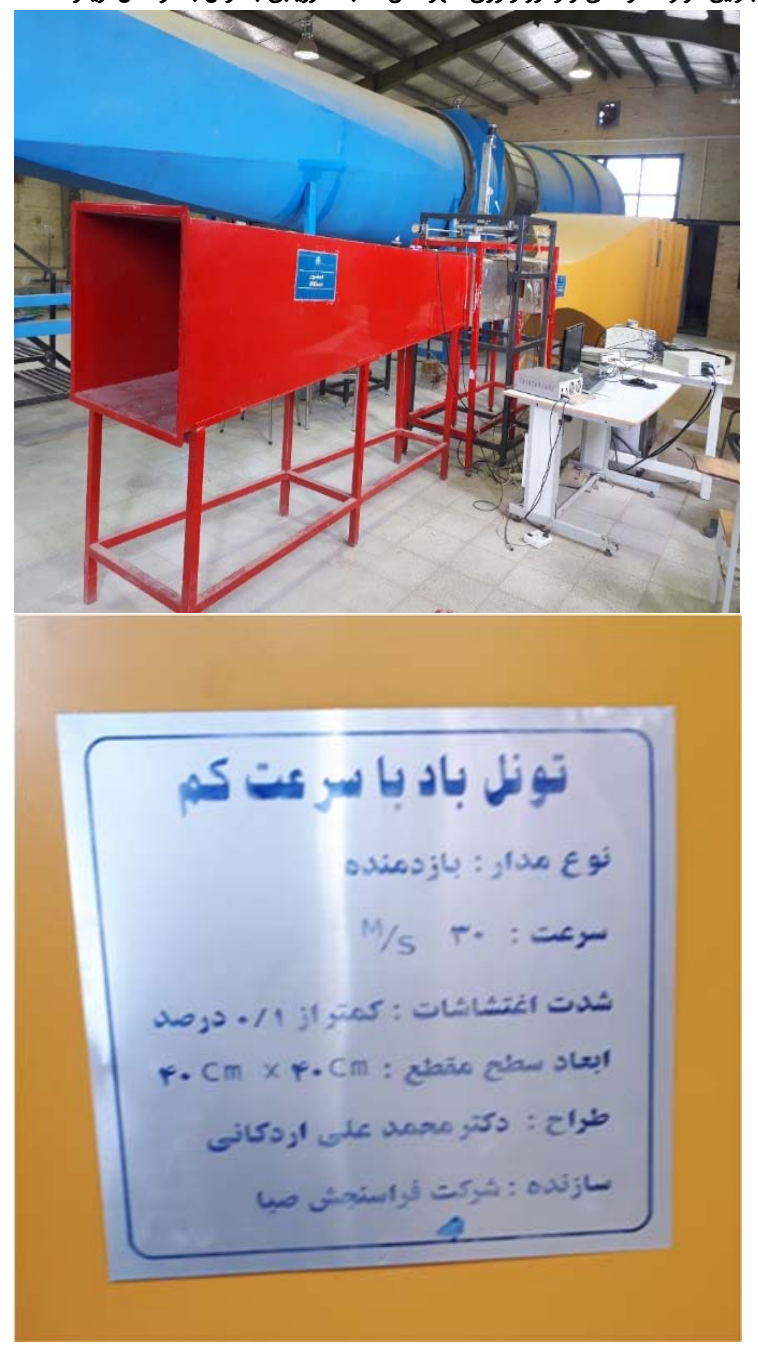

شكل F) تونل باد مورد استفاده جهت بررسى حساسيتيذيرى رخسارهها

يافتهها

نتايج حاصل از اندازهيرى مقدار بادبردگى خاك با دستكاه سنجش

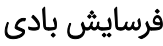

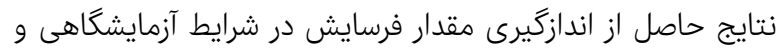

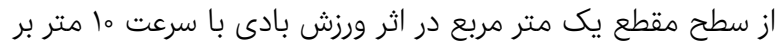

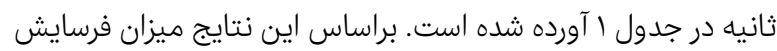

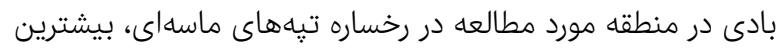

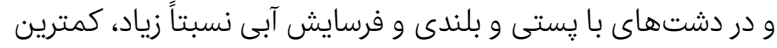

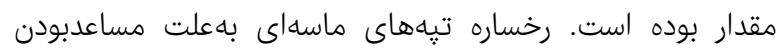

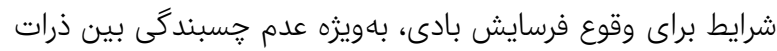

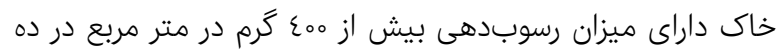

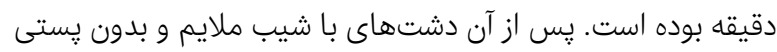

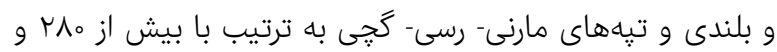

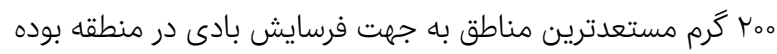

است. نقشه حساسيت به فرسايش بادى در منطقه مورد مطالعه با بررسى

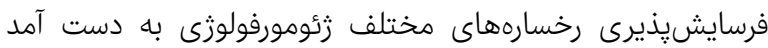

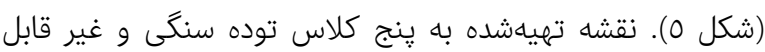

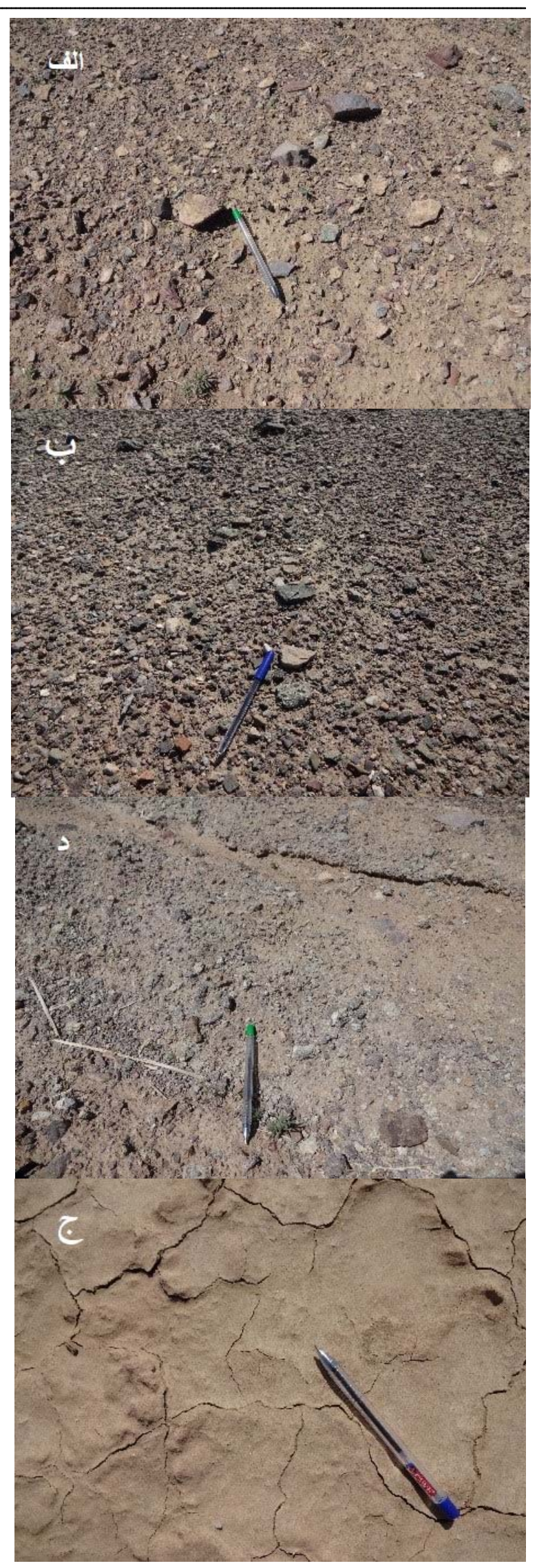

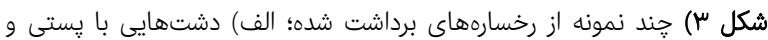

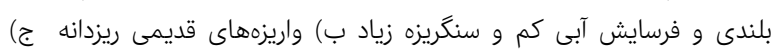

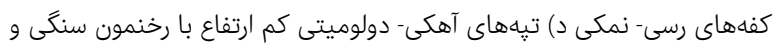

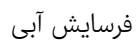


به لحاظ خاى و يوشش سطح آن رخساره تيههاى ماسهاى بيشترين وزن و رخسارههاى دشتهايى با يستى و بلندى كم و سنگ بـريزه زياد و كفههاى رسى- نمكى كمترين وزن را به خود اختصاص داص دادئ دادند.

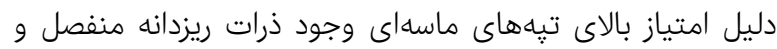

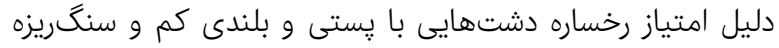
زياد و كفههاى رسى- نمكى به ترتيب، ذرات درشت دانه و اتصال قوى بين ذرات رس و نمك و در واقع سيمانىشدن قوى بين آنها است. بررسى وضعيت يوشش كياهى در منطقه نشان مى بدهد كه

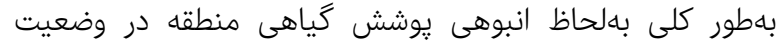

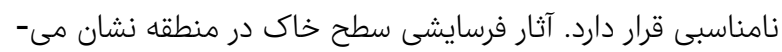

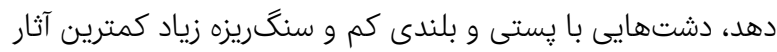

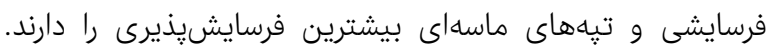

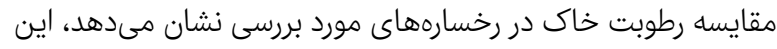

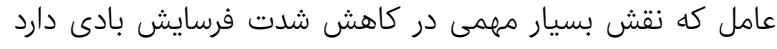

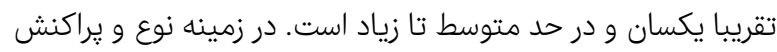

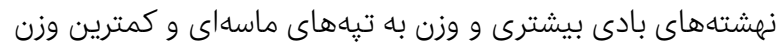

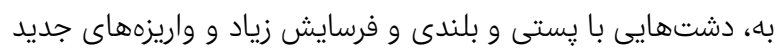

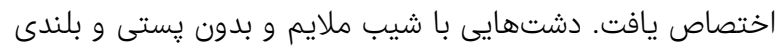

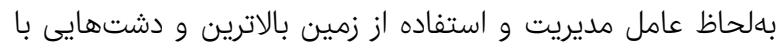

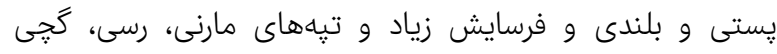
كمترين ميزان را نشان دادند.

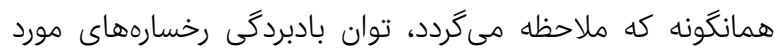

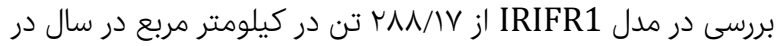
رخساره دشتهاى با پستى و بلندى و فرسايش آبى كم و سنگريزه

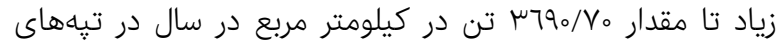

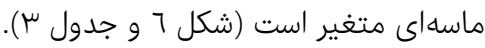

فرسايش، حساسيت خيلى كم، كم، متوسط و زياد مان تقسيم گرديد.

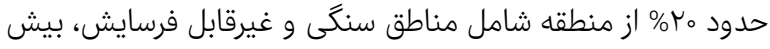

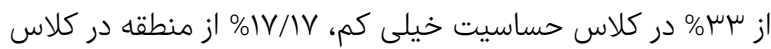

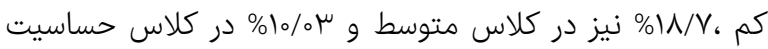

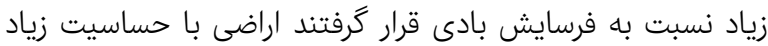

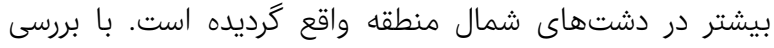

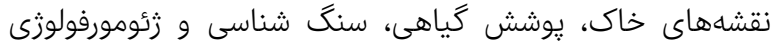
مشخص گرديد كه در اين ناحيه دليل حساسيت زئنسي سياد در برابر فرسايش، وجود تشكيلات ريزدانهاى است كه شامل تيههاي ماسهاى با يوشش نسبتا تنك است، كه شرايط مستعد در برديلات برابر فرسايش بادى را فراهم مىكند. مقاومترين مناطق در برابر فرسايش بـاي

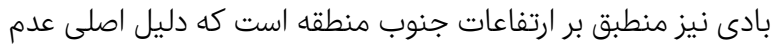
حساسيت آن، وجود خاك با ضخامت كم و رخنمون سنكى است.

IRIFR1 نتايج حاصل از كاربرد مدل وجود حال با صحامل

جدول r امتيازدهى عوامل موثر در فرسايش بادى به به روش IRIFR1

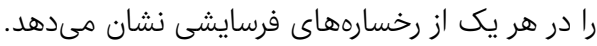

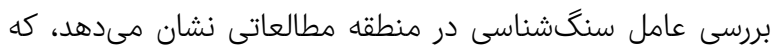

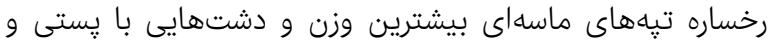

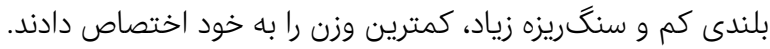

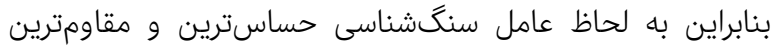
رخساره نسبت به فرسايش بادى به شمار مىروند. مقايسه رخسارهها

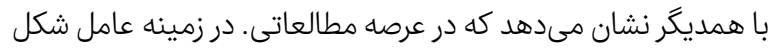

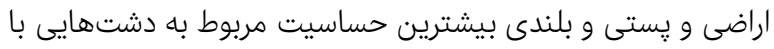

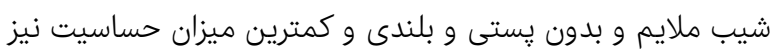

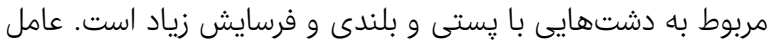

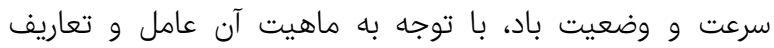

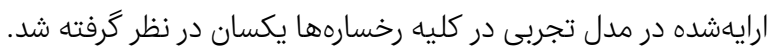

جدول () مقدار خاك برداشت شده در رخسارههاى مختلف شهرستان گناباد به ازاى سرعت ما متر بر ثانيه

\begin{tabular}{|c|c|c|c|}
\hline درصد مساحت & ميزان فرسايش(كرم در مترمربع در ده دقيقه) & نام رخساره & شماره نمونه \\
\hline $10 \% \mu$ & $\varepsilon \cdot \vee / \mu$ & تيههاى ماسهاى & 1 \\
\hline $10 / 71$ & $r Y / 01$ & 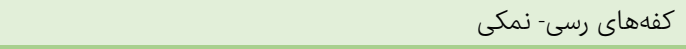 & r \\
\hline $7 / \mathrm{V}$ & rT/Vo & تيههاى آهكى، دولوميتى كم ارتفاع با رخنمون سنكى و فرسايش آبى & $\mu$ \\
\hline$r / \mu \mu$ & $7 \pi / 7 \pi$ & 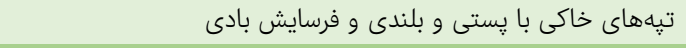 & $\varepsilon$ \\
\hline$\mu / \mu \gamma$ & $r_{0 \circ / \mu V}$ & تيههاى مارنى- رسى- گَجى & 0 \\
\hline$r / 17$ & $7 \varepsilon / q_{0}$ & دشت ريگى ريزدانه & 7 \\
\hline$q / \mu \varepsilon$ & $r r / \Lambda \Lambda$ & دشتهاى با يستى و بلندى و فرسايش آبى كم و سنكريزه زياد & $\checkmark$ \\
\hline $0 / 19$ & $r \Lambda \circ \%$ & دشتهاى با شيب ملايم و بدون پِستى و بلندى & $\wedge$ \\
\hline $1 / 77$ & $\mid V \mu / \mu r$ & دشتهاى نسبتا مسطح با شورى متوسط & 9 \\
\hline $0 / \mu \mu$ & IrE & واريزههاى قديمى ريزدانه & 10 \\
\hline$r / 00$ & $\mid \varepsilon r / \varepsilon_{0}$ & واريزههاى قديمى با بافت متوسط & 11 \\
\hline IT/VV & $\wedge \mathrm{V} / \mathrm{VI}$ & واريزههاى جديد & ir \\
\hline$\mu / 77$ & $\mid r / \varepsilon V$ & دشتهاى با يستى و بلندى و فرسايش آبى نسبتاً زياد & Ir \\
\hline & щN/OO & دشتهاى سيلابى با آبراهه كم عمق & 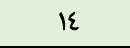 \\
\hline
\end{tabular}




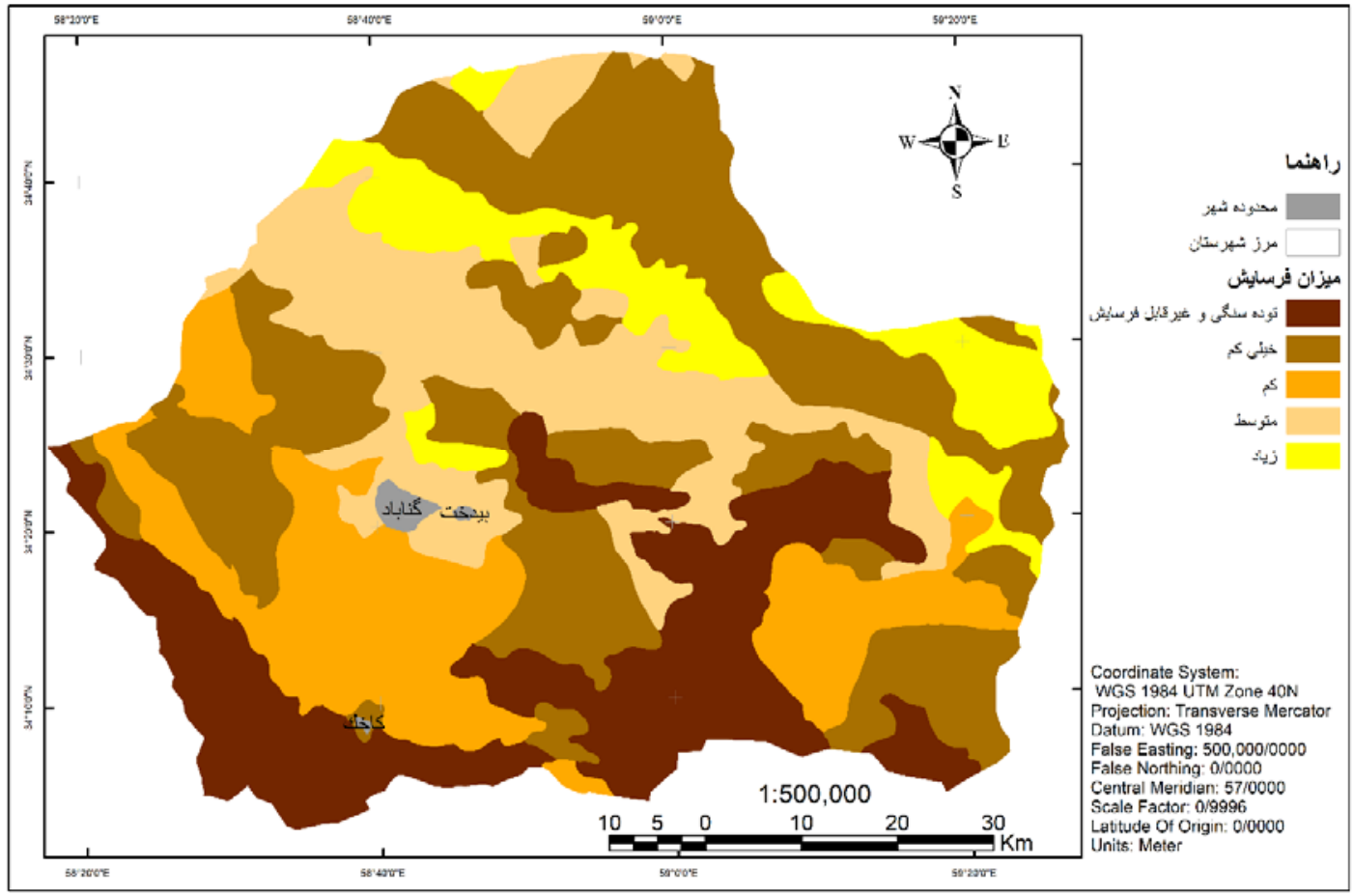

شكل ه) نقشه كلاسهاى فرسايشيذيرى خاك با استفاده از تونل باد

جدول r مقادير برآوردشده فرسايشبادى در منطقه مورد مطالعه به روش IRIFR1

\begin{tabular}{|c|c|c|c|c|c|c|c|c|c|c|c|}
\hline $\begin{array}{c}\text { رسوب ويزه } \\
\text { (ton/Km2/y) }\end{array}$ & جمع & مديريت اراضى & 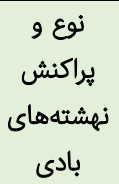 & خاك & سطار فرسايشى & يوششى ئباهى & خاك و & وضعيت و و باد & 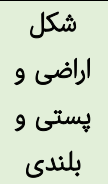 & سنگشناسى & رخسارهها \\
\hline$\mu 790 / V_{0}$ & 90 & 0 & 10 & 1 & $1 \mu$ & v & 10 & 10 & V & 10 & تيههاى ماسهاى \\
\hline mol/qV & $\varepsilon \mu$ & 0 & r & -0 & $\mu$ & $1 \varepsilon$ & w & 10 & v & 0 & كفههاى رسىنمكى \\
\hline$\varepsilon 99 / \varepsilon \wedge$ & 0. & 。 & r & $\varepsilon$ & 7 & ir & $\mu$ & 10 & $\mu$ & 0 & تيههاى آهكى دولوميتى ارتفاع با رخنمون \\
\hline $7 \varepsilon 1 / \mu \varepsilon$ & $\infty$ & 7 & r & $\varepsilon$ & 7 & 0 & $\checkmark$ & 10 & $\varepsilon$ & 7 & تبلندهاى خاكى با يستى و فرسايش بادى \\
\hline $170 / \mathrm{Vr}$ & 71 & $\varepsilon$ & r & $\varepsilon$ & 7 & $\pi$ & $\wedge$ & 10 & $\varepsilon$ & 7 & تيههاى مارنىرسى- گָجى \\
\hline$\varepsilon$ VO/Ir & $\varepsilon 9$ & 0 & r & $\wedge$ & 0 & 0 & 1 & 10 & $\varepsilon$ & $\varepsilon$ & دشت ريكىريزدانه \\
\hline$r \tau \varepsilon / \varepsilon \mu$ & $\mu \varepsilon$ & 0 & r & $\varepsilon$ & r & 0 & $-\varepsilon$ & 10 & $\varepsilon$ & 1 & 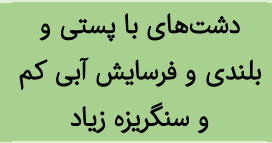 \\
\hline$|9 r 7 / \mathrm{V}|$ & VV & ir & r & $\wedge$ & 10 & س & $\mu$ & 10 & 9 & 0 & دو بدون يستى و با شيب ملايم \\
\hline$\| 11 / 7 \pi$ & TV & 0 & r & $\checkmark$ & 9 & ir & 0 & 10 & v & 0 & دشتهاى نسبتا مسطح با \\
\hline lrov/vr & $V_{0}$ & 0 & 0 & $\wedge$ & 10 & 10 & 0 & 10 & $\checkmark$ & 0 & واريزههاى قديمى ريزدانه \\
\hline $170 / \mathrm{r}$ & 71 & 10 & r & $\varepsilon$ & 0 & ir & $\mu$ & 10 & $\varepsilon$ & 7 & واريزههاى قديمى با بافت \\
\hline$\vee \wedge \mu / \mu \varepsilon$ & 09 & 0 & 1 & 7 & 9 & $1 \varepsilon$ & $\mu$ & 10 & $\varepsilon$ & r & واريزههاى جديد \\
\hline$\mu \circ r / 90$ & $\varepsilon_{0}$ & $\varepsilon$ & 1 & $\varepsilon$ & 0 & 7 & 。 & 10 & r & $\mu$ & 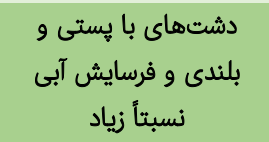 \\
\hline$V \circ \Lambda / \vee q$ & or & $\checkmark$ & $\varepsilon$ & $\varepsilon$ & $\checkmark$ & $\checkmark$ & 。 & 10 & v & 7 & دشتهاى سيلابى با آبراهه كم عمق \\
\hline
\end{tabular}




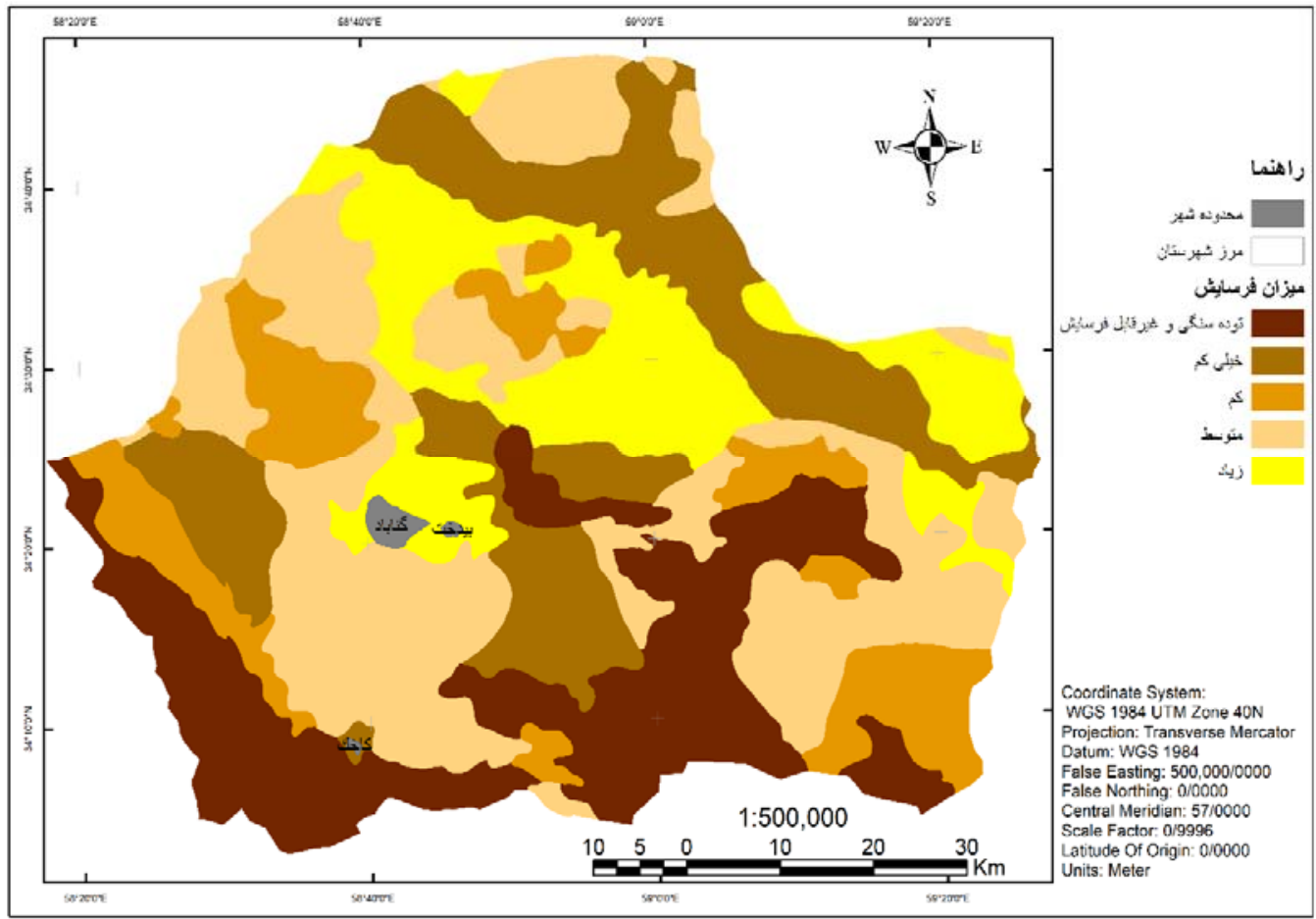

شكل \&) نقشه كلاسهاى فرسايشيذيرى خاك با استفاده از مدل IRIFR1

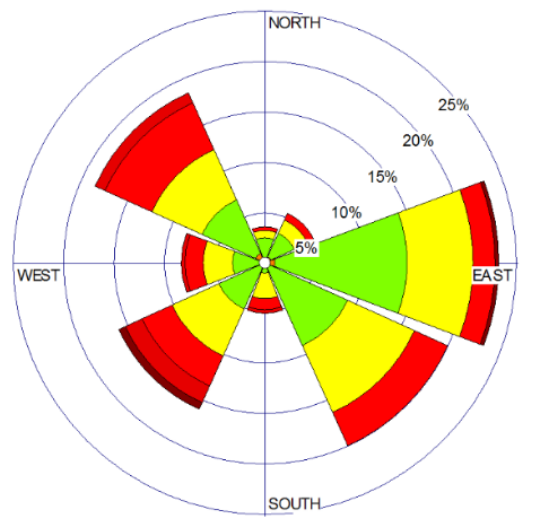

$\underset{(\mathrm{m} / \mathrm{s})}{\text { WNDED }}$

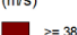

$>=38.0$

$32.0-38$
$26.0-32$

$200-320$

$20.0-26.0$

Calms: $0.00 \%$

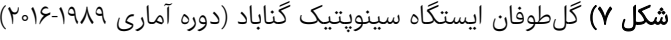

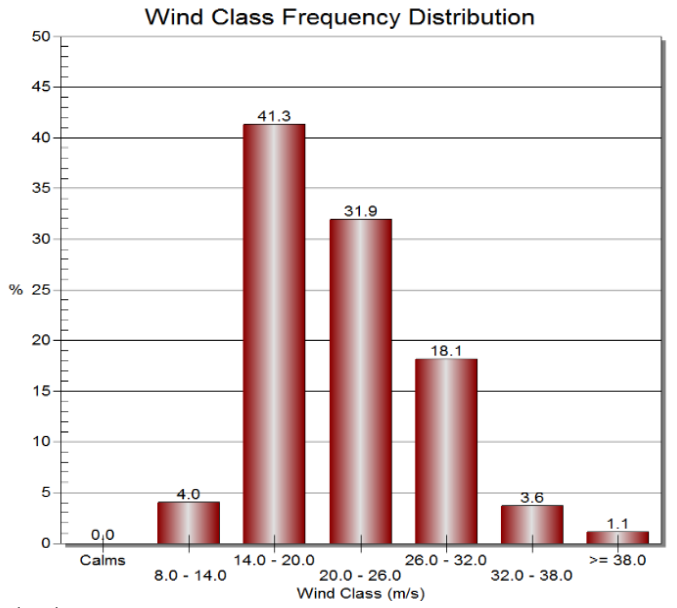

نمودار () توزيع فراوانى كلاسهاى با بيش از ^ متر بر ثانيه در ايستكًاه گناباد
جدول س) مساحت كلاسهاى فرسايشيذيرى خاك در دو روش تونل باد و IRIFR1

\begin{tabular}{|c|c|c|}
\hline $\begin{array}{l}\text { درصد مساحت در روش } \\
\text { IRIFR1 }\end{array}$ & درصد مساحت در روش & ميزان حساسيت \\
\hline$r_{0} / T^{\prime}$ & $r_{0} / T r$ & فرساطق سنكى و غيرقابل \\
\hline$r_{0} / 0 \varepsilon$ & $\mu r / \Lambda O$ & حساسيت خيلى كم \\
\hline $\mid r / T_{0}$ & IV/IV & حساسيت كم \\
\hline $\mathrm{rq} / \mathrm{OH}$ & $|N / \mathrm{V}|$ & حساسيت متوسط \\
\hline $18 / 09$ & $10 \% \mu$ & حساسيت زياد \\
\hline
\end{tabular}

براى تحليل طوفانخيزى در منطقه مورد نظر از نمودار كلطوفان

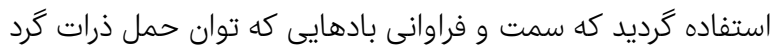

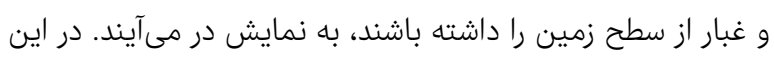

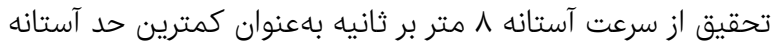

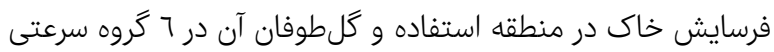

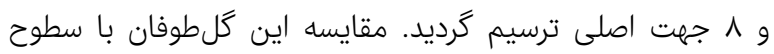

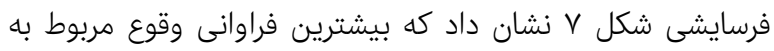

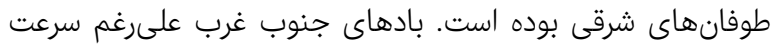

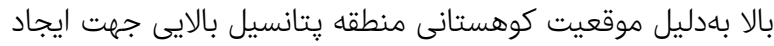

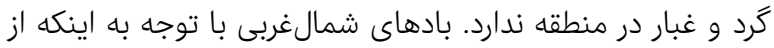

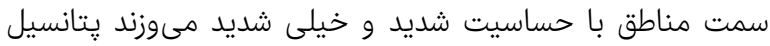

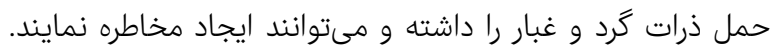

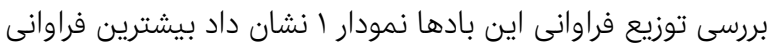

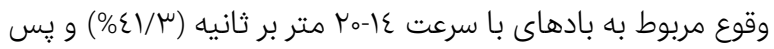

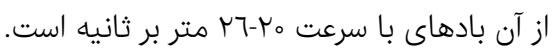




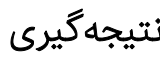

وجود تويوكرافى مسطح و اراضى با شيب كم در بخشهاى شمالى

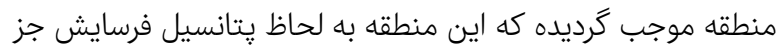

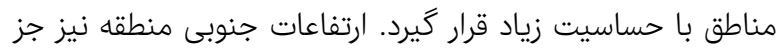

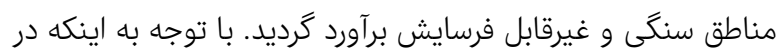

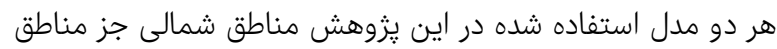

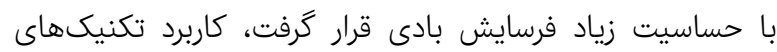

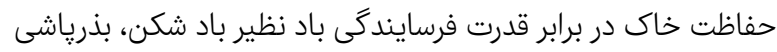

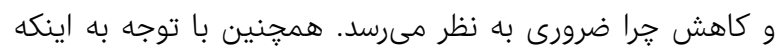

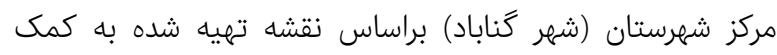

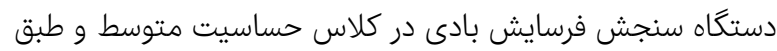

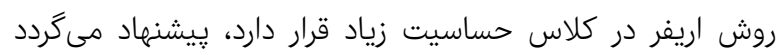

اقدامات لازم در جهت تثبيت رسوبات از اين رخساره آغاز گردد.

تشكر و قدردانى: اين مقاله مستخرج از طرح يزوهشى شماره

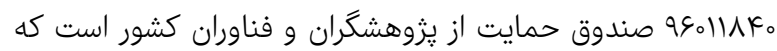

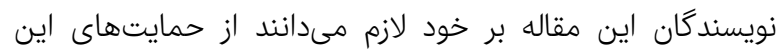
صندوق تقدير و تشكر نمايند.

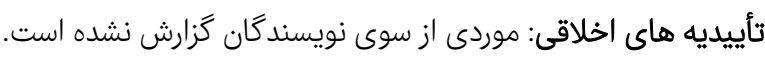

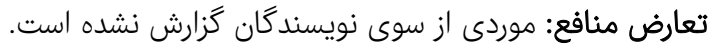

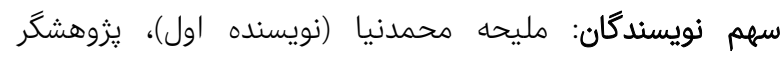

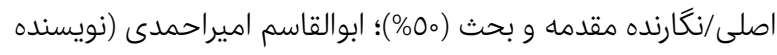

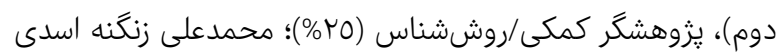

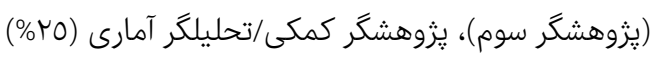

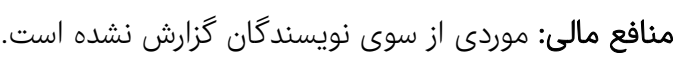

منابع

Alipour H, Hasheminasab S N, Hatefi Ardakani AH, Gholamnia A, Shahnavaz, Y (2014). Estimating wind erosion potential and sediment potential using the IRIFR method in Miandasht Esfarayen Region. Journal of Spatial Analysis of Environmental Hazards. 1(2):77-92. [Persian] Alipour N, Farzanehpey F, Torabir A, Bakhshinia S, Mesbahzadeh T (2016). Estimation of wind erosion severity in Alaa Region of Semnan using IRIFR.E.A model. Journal of Desert Ecosystem Engineering. 5(10):99-107. [Persian]

Amin P, Taqizadeh Mehrejerdi R (2016). Investigating soil erodibility in arid and hyper-arid regions of Iran case study: Yazd-Ardakan plain. Journal of Quantitative Geomorphology Research. 5(2):20-35. [Persian]

Azim Zade MR, Ekhtesasi MR (2004). Investigating the effect of physical and chemical properties of soil on the rate of wind erosion speed, case study: Yazd-Ardakan plain. Journal of Rangeland and Desert Research. 2:225237. [Persian]

Ayazi Z, Mesbahzadeh T, Ahmadi H, Mashhadi N (2016). Investigating the possibility of sedimentation in geomorphological fancies using wind tunnel and IRIFREA, case study: Aran district of Kashan. Journal of Desert Management. 8:70-83. [Persian]

\section{بحث}

در اين تحقيق از مدل فيزيكى - آزمايشكاهى كاربرد دستخاه تونل باد

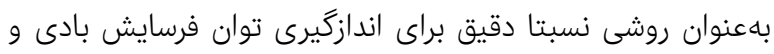

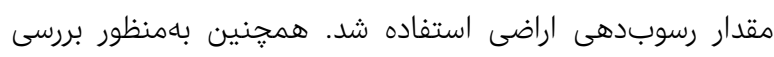

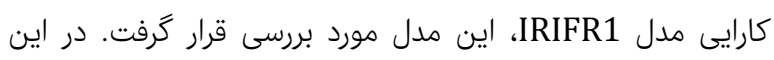
يزوهش، براى تعيين شدت فرسايش بادى نقشيه رخسارههاى

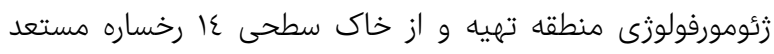

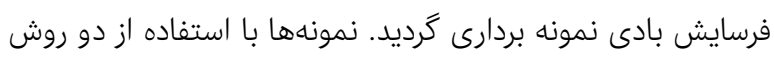

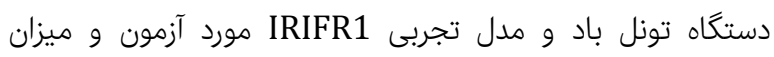

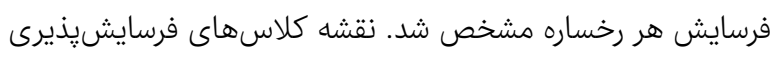

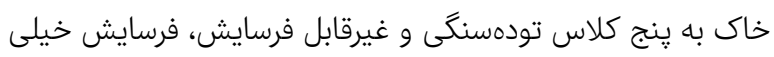

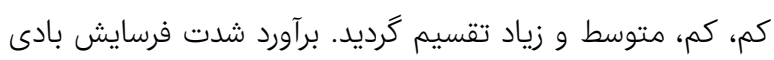

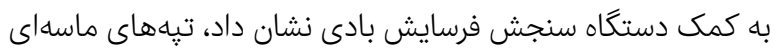

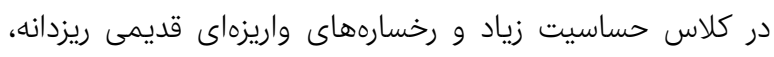
دشتهاى سيلابى با آبراهه كم عمق، دشتهاى دراس نسبتا مسطح باري

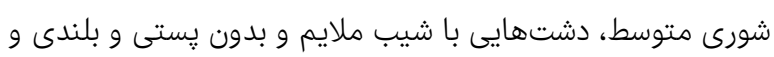

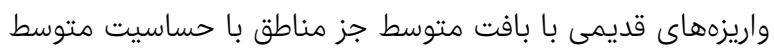

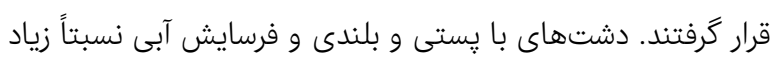

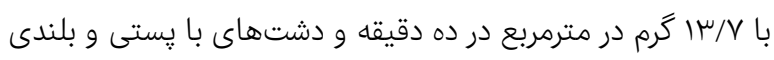

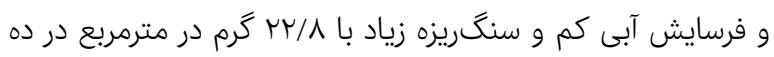

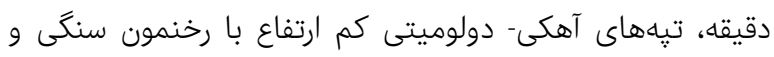

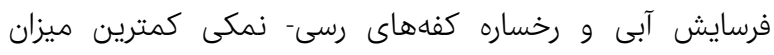

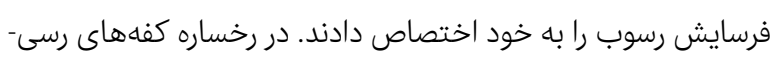

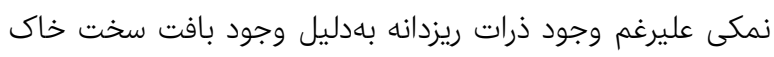

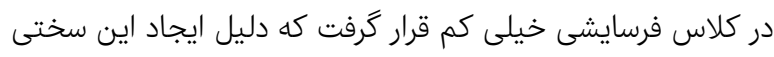

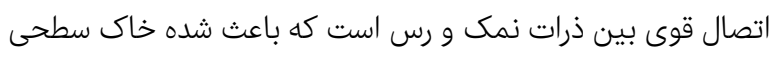

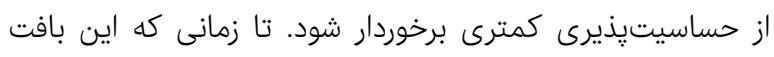

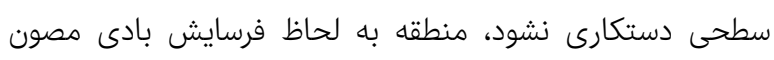

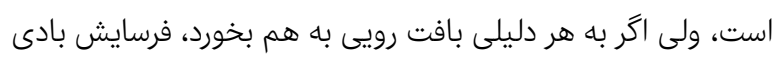

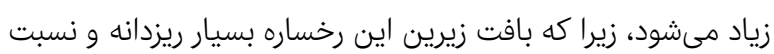

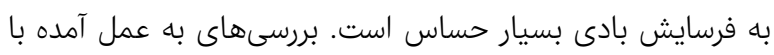

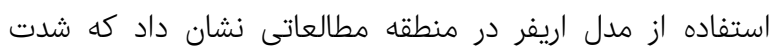

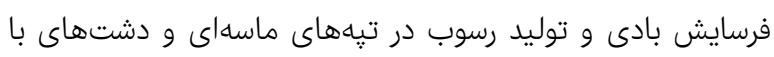

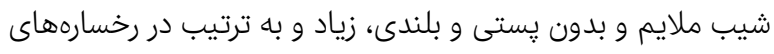

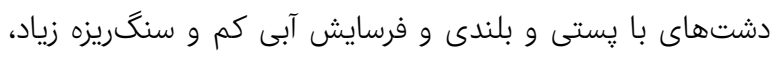

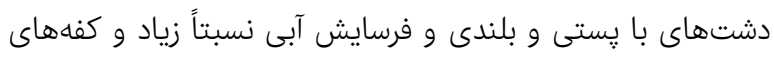

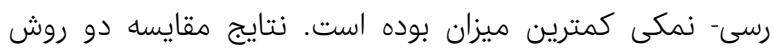

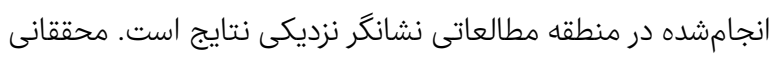
[Kochemi Sardo et al, همجون كوجمى ساردو و همكاران

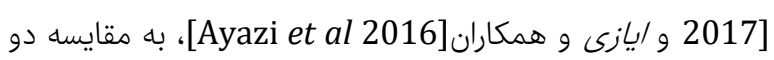

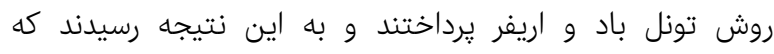

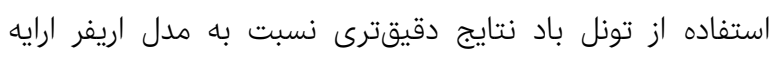
مى مدر. 
Canvas Quarterly. 7(1):13-25. [Persian]

Kusumandari A (2014). Soil erodibility of several types of green open space areas in Yogyakarta city, Indonesia. The 4th International Conference on Sustainable Future for Human Security. Procedia Enviromental Sciences. 20:732-736.

Memarian Khalil Abad H, Safdari AA (2008). Deposits of wind deposits in the fedsheh area of Neyshabur. Journal of Rangeland and Desert Research. 15(1):41-26. [Persian] Mohammad Khan S, Kashfi F S (2015). The directions of winding sand in Ardestan region by comparing morphometric time of sand dunes and wind characteristics. Journal of Quantitative Geomorphology Research. 4(1):59-74. [Persian]

Movahedan M, Abbasi N, Keramati Targhi M (2013). Laboratory study of the effect of polyvinyl acetate on the erosion of various soil soils against sand. Journal of Soil and Water Conservation Research. 20(1):55-76. [Persian] Saremi Naieni MA (2016). Estimate the frequency of speed and the direction of the erosion of winds and produces dust storms and dust at the level of Yazd province using the windrose analysis. Desert Management Journal. 1(8):96-106. [Persian]

Sharratt B, Feng G, Wendling L (2007). Loss of soil and PM10 from agricultural fields associated with high winds on the Columbia plateau. Earth Surface Processes and Landforms. 32(4):621-630.

Webb NP, Galloza M S, Zobeck TM, Herrick J E (2016).

Threshold wind velocity dynamics as a driver of aeolian sediment mass flux. Aeolian Research. 20:45-58.

Zobeck TM, Van Pelt RS (2006). Wind-induced dust generation and transport mechanics on a bare agricultural field. Journal of Hazardous Materials. 132(1):26-38.
Ebrahimi Dorcheh K, Jannat Rostami M, Jalali M, Ja'farian A (2010). Estimating wind erosion via IRIFREA. National Conference on Watershed Management and Engineering. 2010, 28-29 April: Noor. pp. 1-8. [Persian]

Ekhtesasi MR, Zare Chahouki A (2006). Wind erosion values of IRIFER model and comparison with wind erosion meter case study: Segzi plain in Esfahan province. Iranian Journal of Range and Desert Research. 23(2):255264. [Persian]

Fister W, Ries J B (2009). Wind erosion in the central ebro basin under changing land use management. Field experiments with a portable wind tunnel. Journal of Arid Environments. 73(11):996-1004.

Hangen LJ (1976). A wind erotion predication system to meet user needs. Soil Water Conserve Journal. 46(2): 106111.

Hanifeh Pour M, Mashhadi N (2013). Survey of agricultural resistance to wind erosion in southeast Damghan. Journal of Geography and Environmental Studies. 2(6):100-110. [Persian]

Ildermi A, Moradi M (2017). Estimating wind erosion intensity using the IRIF.E.A model case study: Ghahavand plain of Hamadan. Journal of Geography and Planning. 21(60):35-52. [Persian]

Jafari Shalkuhi A, Vafayian M, Roshan zamir MA, Mir Mohammad Sadeghi M (2015). Evaluating effective factors on the stabilization of mineralized soils against wind to prevent the accumulation of microorganisms. Iranian Journal of Soil and Water Sciences. 19(73):273286. [Persian]

Kochemi Sardo E, Basalat Pour AA, Boshra H, Shirani H, Esfandiar Pour Brojani E (2017). Evaluation of the IRIFR model for simulating soil loss in different facies of Wind Erosion Using Wind Erosion Measurement Data. Dry 